\title{
$10 \%$ povidone-iodine versus $2 \%$ chlorhexidine gluconate for Periurethral cleansing before catheterization among hospitalized patients: A randomized controlled trial
}

\section{elham vahabi}

Isfahan University of Medical Sciences

somayeh ghafari ( $\nabla$ somayehghafari@nm.mui.ac.ir)

Isfahan University of Medical Sciences https://orcid.org/0000-0001-9331-0902

somayeh haghighat

Isfahan University of Medical Sciences

\section{Research article}

Keywords: $10 \%$ povidone, iodine, $2 \%$ chlorhexidine gluconate, Bacteriuria, Periurethral cleansing

Posted Date: September 25th, 2019

DOl: https://doi.org/10.21203/rs.2.14793/v1

License: (c) (1) This work is licensed under a Creative Commons Attribution 4.0 International License.

Read Full License 


\section{Abstract}

Background There are evidences that periurethral cleaning by antiseptics before catheterization decreases the risk of urinary tract infections. The purpose of this study was to Comparing $10 \%$ povidoneiodine and chlorhexidine gluconate $(\mathrm{CHG})$ effectiveness in periurethral cleaning before catheterization on bacteriuria and pyuria in hospitalized patients.

Methods A randomized controlled trial was used, and subjects were randomly allocated to either the $10 \%$ povidone -iodine group or the $2 \%$ chlorhexidine gluconate group. Urine specimens for culture and Analyse were collected 3 times for each subject within 5 days.

Results Overall, 216 urine samples were collected in 72 subjects .There were no significant difference in results of bacteriuria of two groups immediately, $72 \mathrm{hrs}$. and 5 days after catheterization $(p>0.05)$. There was no significant difference between two groups regarding positive pyuria immediately after sampling ( $p>0.05$ ). Although its amount was significantly higher $72 \mathrm{hrs}$ and 5 days after catheterization in $10 \%$ povidone-iodine group than $2 \%$ chlorhexidine gluconate $(p<0.05)$. In order to evaluate average of microorganism in different time intervals between two groups Mann- Whitney test was used. This test showed that there was no significant difference of number of time intervals $(p>0.05)$.

Conclusions The results of this study showed that using $2 \%$ chlorhexidine gluconate reduced the amount of bacteriuria in catheterazied patients compared to $10 \%$ povidone-iodine. However this difference was not significant. Therefore doing more studies with more number of samples in this field is suggested. Trial registration: Retrospectively registered. IRCT20170712035044N2

Key words: $10 \%$ povidone-iodine- $2 \%$ chlorhexidine gluconate - Bacteriuria- Periurethral cleansing

\section{Background}

Hospital Aquired infection (HAl) is the most prevalent unwanted event due to offering health care services among hospitalized patients which can increase mortality and it can impose economic burden on society too. HAl is an infection which did not exist or was not in stage of commune in the time of patient hospitalization and arise after 48 hours of hospitalization in hospital and days of 7 to 30 after releasing (1). Indifferently $7 \%$ of patients in industrial countries and $10 \%$ in developing countries infect to a kind of HAl during the time of hospitalization(2). According a report from Centers for Disease Control and Prevention (CDC) in the U.S, health expenses directly arising from HAl is estimated around $35 / 5$ to 45 billion dollars a year and this amount increases to 7 billion euros in Europe, however there is not exact data from developing countries (3). Catheter-associated urinary tract infection (CAUTI) is one of the most prevalent kinds of HAI. $12 \%$ to $16 \%$ of adults who hospitalized to investigate the urine output during an acute illness or after a surgery, curing urinary retention and for the aims of diagnostic and therapeutic have to use catheter (4).Using catheter disposes patients to UTI, so that each day having catheter increases the risk of bacteriuria infection from 3\% to 7\% (5).Some of important bacteriuria infection related to catheter form a big storage of organisms resistant to antibiotics, upper and lower UTI, 
bacteremia, repetitive flues, kidney and bladder stone formation and as a result increasing the time of hospitalization and health care costs(6).Micro-organisms enter the urinary system by two ways of external and internal tract but prevalently and specially in women, by entering catheter into urinary tract microbe which are around urethra and perineum stick to the surface of catheter and enter the bladder and make conditions for bacteria colonization in urine (7).Estimations show that 65 to 70 percent of CAUTI can be prevented by infection control actions (8). If health care agents don't observe UTI control actions like washing hands, periurethral cleaning before catheterization and doing sterile techniques while entering and exiting catheter rapidly, patients are susceptible for UTI (9).In recent years many studies were probed in order to reduce CAUTI. From those some are related to using catheters containing antimicrobial combinations, anti septic zing areas around catheter and cleaning bladder. There are some evidences that per urethral cleaning by antiseptics before catheterization reduces the risk of CAUTI (10).

In a paper about urinary catheters and ways of preventing hospital infections which was published by Clayton in 2017, using a kind of antiseptic for periuterthral cleaning before catheterization was suggested (11).

According CDC guideline, an antiseptic or sterile lotion is needed for periurethral cleaning before catheterization. However the kind of antiseptic lotion was not stated (5).Despite is known as the most prevalent antiseptic used for skin antisepticizing and periurethral cleaning before catheterization, today some studies are doing by the aim of finding more suitable lotions according to less hospitalize infections faster effects and more economical versus other investigational combinations. As an antiseptic CHG has similar anti microbe effects to like povidone-iodineun but CHG don't lose its properties encountering blood or serum protein also creates longer antiseptic effects on skin. In different researches CHG had better function than in povidone-iodineand skin and surgery area antisepticising (12). While there are contradictory results related to cleaning before catheterization which poses necessity for doing more research. Nasiriani (2009) defined water more economical than $10 \%$ povidone-iodinefor periurethral cleaning before catheterization in women patients regarding bacteriuria.

Dezkaya (2017) and cheung (2008) stated that chlorhrxidine is more effective than $10 \%$ povidone-iodine and Saline solution in decreasing bacteriuria while in a study by Fasougba (2017)there was not a significant difference between antiseptics containing water and Saline solution regarding the degree of UTI after catheterization. Therefore this research compared $10 \%$ povidone-iodineand and $\mathrm{CHG}$ in order to suggest more effective antiseptic in reducing bactereuria in catheterized women patients.

\section{Methods}

\section{Aim}

The aim of this study was to Comparing $10 \%$ povidone-iodine and chlorhexidine gluconate (CHG) effectiveness in periurethral cleaning before catheterization on bacteriuria and pyuria in hospitalized patients. 


\section{Design}

This study was originally designed and conducted as a randomized controlled trial, comparing either $2 \%$ chlorhexidine gluconate with $10 \%$ povidone -iodine in preparation prior to urinary catheterization in women patients.

\section{Setting}

The study was conducted in the emergency department of hospital.

\section{sample}

The study sample thus totaled of 72 women patients above 18 years old and who met inclusion criteria were approached for study participation. The inclusion criteria for the study were (1) the need of catheter urinary tract for five days,(2) having no affection to UTI,(3) and the flu above $38^{\circ}$ while entering the study, (4) having no allergy record to antiseptics in the study, (5)having no clear injury in urethra and (6)having no catheter in the time of admit. Patients eligible for the study were informed of the study and informed consent was obtained in writing. Following consent, patients were randomly assigned to two groups. The groups were $10 \%$ povidone-iodine (group 1), chlorhexidine gluconate (group 2). Patient characteristics were collected for each subject, including age, triage, and the patient's diagnosis and other data was registered in questionnaire for next followings.

\section{intervention}

The standard protocol for urinary catheter insertion was followed in two groups. This protocol involved routine handwashing with antiseptic solution, use of sterile gloves, use of a non-contact technique, and exposing only the tip of the catheter from its plastic sheath when inserting the catheter. the labia minora were separated with the fingertips of one hand. The perineal area was swabbed from front to back, and center outwards with sterile gauze soaked in either $10 \%$ povidone-iodine or $2 \%$ chlorhexidine gluconate. After a minute for drying, the lubricated end of the catheter was gently inserted into the urethra until urine flow appeared (13). A urine sample was taken immediately after catheterization and sent to laboratory at least $2 \mathrm{hrs}$. later and collected urine specimens again at the end of 72 hours and 5 days after catheterization.

The study was conducted according to the hospital microbiology protocol for processing urine cultures. Urine sample in sheep blood $(\mathrm{BHI})$ agar was cultured. Cultures were incubated aerobically at $37^{\circ} \mathrm{C}$ for 24 to 48 hours. After incubation, the agar plate was examined,and the number of colonies for each type of microorganism was counted. Cultures showing a pure growth $>10^{3}$ organisms per liter were subject to full identification and the WBC $\geq 10^{3} \mathrm{HPF}$ pyuria was taken positive. Types of microorganisms were identified. 
Probable bacteria pathogens were considered to be E. coli, Klebsiella spp., Enterobacter spp., Enterococcus spp., Proteus spp., and Pseudomonas spp(14).

This study adheres to CONSORT guidelines and include a completed CONSORT flow diagram (diagram 1).

\section{Data collection}

A demographic questionnaire was administered to collect demographic characteristics (i.e. age, sex, the cause of admission), and urine specimens.

\section{Statistical Analyses}

The Statistical Package for the Social Sciences for Windows 16.0 (SPSS Inc., Chicago, IL, USA) was used for statistical analyses. Data was expressed as number, percentage, mean and standard deviation. Characteristics of the 2 groups were compared using the $\chi 2$ or Fisher exact test.

\section{Results}

Results showed that the most prevalent reason of patient's hospitalization in CHG was pain in belly and in $10 \%$ povidone-iodine group was stroke. $50 \%$ of patients in CHG group had level 2 of triage while $27 / 7 \%$ of $10 \%$ povidone-iodine group had level 1 of triage. The most recorded disease was cardio vascular among all patient. $63 / 9 \%$ of patients in $\mathrm{CHG}$ and $75 \%$ of $10 \%$ povidone-iodine group had NPO diet. Data analysis showed no significant difference between two basic variables $(P>0 / 05)$.

This research compared three parameters of number of micro-organism bacteriurea amount and pyuria immediately, 72 hours and 5 days after catheterization between two groups.Chi-Square test results showed that positive bacteriuria frequency after catheterization in three different times had no significant difference between two groups ( $P>0 / 05)$. (Table 1 )

There was no significant difference of positive pyuria immediately after sampling between two groups $(P>0 / 05)$. However 72 hours and 5 days after catheterization it's amount was significantly higher in $10 \%$ povidone-iodine group than $\mathrm{CHG}(\mathrm{P}<0 / 05)$. Number of micro-organism did not follow a normal distribution in three times,. Therefore the researcher used Mann-Whitney test to compare mean number of micro-organism in different times between two groups. The results of the test indicated that microorganism number had no significant difference in none of three times between two groups $(P>0 / 05)$. (Table 3).

Samples containing positive bacteriuria and pyuria were not omitted from research and bacteriuria and pyuria increase in three times after intervention were compared. In first urine culture (immediately after catheterization), $16 / 7 \%$ of positive bacteriuria was seen in $\mathrm{CHG}$ while it was $19 / 4 \%$ in $10 \%$ povidoneiodine group. According results of CHG group, bacterioria increased to $41 / 6 \%, 72$ hours after 
catheterization. For the $10 \%$ povidone-iodinegroup this increase was $58 / 2 \%$. CHG group had $80 / 5 \%$ and $10 \%$ povidone-iodine group $75 \%$ of positive bacteriuria after 5 days of catheterization.

Ecoli was the most frequent cultured bacteria in $\mathrm{CHG}$ by $55 \%$ and in $10 \%$ povidone-iodinegroup by $42 \%$. Chi-Square test results indicated no significant difference between two groups in terms of frequency distribution of micro-organism species $(P>0 / 05)$.

\section{Discussion}

According findings of the study, positive bacteriuria and micro-organism number had no significant difference between $\mathrm{CHG}$ and $10 \%$ povidone-iodine group 72 hours and 5 days after catheterization, while amount of pyuria was significantly higher in $10 \%$ povidone-iodine group 72 hours after catheterization compared to $\mathrm{CHG}$ group. There are few researches around comparing amount of bacteriuria in periurethral cleaning by antiseptics before catheterization. Most comparisons were between antiseptics and sterile or unsterile water. Results of Cheung et al(2008) that aimed at comparing water and CHG on periurethral cleaning before catheterization in patients indicated that positive bacteriuria seven days after catheterization in $\mathrm{CHG}$ group was $60 \%$ and in sterile water was $75 \%(15)$

In present research positive bacteriuria in $\mathrm{CHG}$ increased to $80 \%$ after 5 days which doesn't have consistency with results of Cheung study. Inconsistency is due to different criterion of measurement. In Cheung research, amount of positive bacterioria was considered $\mathrm{cfu} / \mathrm{mL} 10^{5}$ while in our research was more than $\mathrm{cfu} / \mathrm{mL} 10^{3}(14)$.

Ifer kara et al(2017) conducted a research titled 'Effects of cleaning urethra by three lotions of water, sterile water and $10 \%$ povidone-iodine on amount of bacteriuria in cathetered patients"(16).In their research there was no significant difference between two groups regarding bacteriuria amount. Therefore in these studies $\mathrm{CHG}$ and $10 \%$ povidone-iodine had the same antibacterial effects rather than other lotions. However the aim of present research is the comparison between $2 \%$ chlorhexidine gluconate and $10 \%$ povidone-iodineon bacteriuria level in catheterized patients.

Düzkaya et al (2017) conducted a study titled "providine-lodine, chlorhexidine gluconate, or water for periurethral cleaning before indwelling urinary catheterization in pediatric intensive care". The subjects were kids from 1 month to 18 years old (9).The patients were divided into 3 groups of 40 . Then urethral cleaning was done by $10 \%$ povidone-iodine,chlorhexidine gluconate or sterile water, depending on the group.

Every 3 days, a urine sample was sent and amount of UTI and clinical symptom was checked. The result showed that $15 \%$ of patients of $10 \%$ povidone-iodine, $4 / 5 \%$ of $\mathrm{CHG}$ and $7 / 5 \%$ of sterile water groups were affected to UTI. Amount of positive bacteriuria was not pointed out in this study. On the other hand according to UTI definition due to catheterization, bacteriuria and pyuria should be probe with one another(17). Pyuria amount was not investigated in Düzkaya research.In present research, positive bacteriuria amount was $41 \%$ in $\mathrm{CHG}$ group and $58 \%$ in $10 \%$ povidone-iodine group, while positive pyuria 
amount after 72 hours and 5 days of catheterization in CHG group significantly lower th $10 \%$ povidoneiodinean group. Despite present differences in choosing patients, hospital sections and number of samples, in both studies, amount of positive bactriuria was lower in $\mathrm{CHG}$ rather than $10 \%$ povidone-iodine after 3 days of catheterization, which are consistent with each other. Effects of CHG on amount of bacteriuria of catheterized patients was probed by other methods too. Wikström et al (2018), conducted a research by title of "Bladder irrigation with $\mathrm{CHG}$ reduces bacteriuria in persons with spinal cord injury. They chose 19 patients with spinal cord injury who had more than $10^{5} \mathrm{cfu} / \mathrm{mL}$ bacteria in their urine. Their bladder was cleaned by $0 / 02 \%$ chlorhexidine gluconate two times a day. As a result after cleaning by chlorhexidine gluconate the amount of bacteriuria was reduced in 14 member $(74 \%)$ of subjects(18).Samimi et al (2010), compared the effects of $2 \%$ chlorhexidine gluconate and sodium chloride $9 \%$ in patients with spinal cord injury with catheterization by the same method. Results revealed that cleaning bladder by chlorhexidine gluconate reduces UTI in subjects after catheterization two times more than sodium chloride 9\% (19).Azadmanesh et al (2014) conducted a research in which cleaning catheterization place by chlorhexidine gluconate and $10 \%$ povidone-iodine was done for 75 stroke affected patients, 24 hours after catheterization. In their study bacteriuria and pyuria was probed. In bcteriuria $2 \%$ chlorhexidine gluconate and $10 \%$ povidone-iodine were (respectively $16 \%$ and $20 \%$, P.value:0/7) and pyuria (respectively $20 \%$ and $32 \%$, P.value:0/6) which reveals that $2 \%$ chlorhexidine gluconate did better than $10 \%$ povidone-iodine (20). The present study was conducted to compare effect of $2 \%$ chlorhexidine gluconate $10 \%$ povidone-iodinean on periurethral cleaning before catheterization in hospitalized women patients. Since it was decided to choose patients who have not have catheter before, the project was done in emergency section.

\section{Limitation}

We can mention patient's acute clinical situations, socializing clients and personnel in section, repetitive movements of patients for paraclinical actions like CT scan and endoscopy as limitations of the study that cause problems in taking care of catheter. Therefore the researcher suggests more studies in other hospital sections with better clinical situations.

\section{Conclusion}

Results of this research reveal that using $2 \%$ chlorhexidine gluconate for periurethral cleaning decreases patient's amount of bacteriuria compared to $10 \%$ povidone-iodine. Although there was no significant difference between two groups, amount of positive pyuria in CHG group was significantly lower than $10 \%$ povidone-iodine group, 72 hours and 5 days after catheterization.

Since $\mathrm{CHG}$ has less side effects, more researches are suggested about using it. If the new studies confirm it's effectiveness on reducing bacteriuria and pyuria on periurethral cleaning,we can reduce UTI in catheterized patients.

\section{Declarations}




\section{Abbreviations}

HAI: Hospital Aquired infection; CDC: Centers for Disease Control and Prevention; CAUTI: Catheterassociated urinary tract infection; CHG: chlorhexidine gluconate; Statistical Package for the SPSS: Social Sciences; UTI: Urethral Tract Infection.

\section{Ethics approval and consent to participate}

This study was funded by Isfahan University of Medical Sciences and approved by the Ethics Committee of Isfahan University of Medical Sciences Code of ethics: IR.MUI.RESEARCH.REC.1397.378. Written informed consent was obtained from all participants. Participations were randomized into two groups. The results of the study were saved into a secret file.

\section{Consent for publication}

Not Applicable.

\section{Availability of data and material}

We do not wish to share our data as we have promised all participants a confidential presentation of the findings. We believe that sharing the data might make it possible to identify individual participants.

\section{Competing interests}

The authors declare no conflicts of interest.

\section{Funding}

This research was supported by Isfahan University of Medical Science (grant number: 397139). Isfahan University of Medical Science has been responsible for the costs of urine analysis tests as well as the equipment needed for the study.

\section{Authors' contributions}

Gh.S, V.E, H.S designed the study. Gh.S, V.E, H.S collected the data. V.E analyzed the data. Gh.S, and V.E prepared the manuscript. All authors approved the final version for submission.

\section{Acknowledgements}


The researcher appreciates the authorities of Alzahra Hospital (affiliated to Isfahan University of Medical Sciences) and all patients participating in this study.

\section{References}

1.Andreoli TE, Fitz JG, Benjamin I, Griggs RC, Wing EJ. Andreoli and Carpenter's Cecil Essentials of Medicine E-Book: Elsevier Health Sciences; 2016.2.WHO WHO. Guidelines on core components of infection prevention and control programmes at the national and acute health care facility level: World Health Organization; 2016.

3.Zarb P, Coignard B, Griskeviciene J, Muller A, Vankerckhoven V, Weist K, et al. The European Centre for Disease Prevention and Control (ECDC) pilot point prevalence survey of healthcare-associated infections and antimicrobial use. Eurosurveillance. 2012;17(46):20316.

4.UTI C-a. Urinary Tract Infection (Catheter-Associated Urinary Tract Infection [CAUTI] and Non-CatheterAssociated Urinary Tract Infection [UTI]) and Other Urinary System Infection [USI]) Events. 2015.

5.Gould CV, Umscheid CA, Agarwal RK, Kuntz G, Pegues DA, Committee HICPA. Guideline for prevention of catheter-associated urinary tract infections. Infection Control \& Hospital Epidemiology. 2017;31(4):31926.

6.Zarinfar N, Valikhani M, Sadeghi B, Soufian M, Akbari M. Prophylactic Effect of Probiotic Capsule (Lactocare) on Urinery Tract Infection of Cateterized Intensive Care Unit Patients. Majallah-i dānishgāh-i \ulūm-i pizishkī-i Arāk. 2017;19(11):47-56.

7.Morello JA. Bailey and Scott's Diagnostic Microbiology. JAMA. 2014;248(16):2056-7.

8.Stevens LA, Claybon MA, Schmid CH, Chen J, Horio M, Imai E, et al. Evaluation of the Chronic Kidney Disease Epidemiology Collaboration equation for estimating the glomerular filtration rate in multiple ethnicities. Kidney international. 2011;79(5):555-62.

9.Düzkaya DS, Uysal G, Bozkurt G, Yakut T, Çitak A. Povidone-lodine, $0.05 \%$ Chlorhexidine Gluconate, or Water for Periurethral Cleaning Before Indwelling Urinary Catheterization in a Pediatric Intensive Care: A Randomized Controlled Trial. Journal of Wound Ostomy \& Continence Nursing. 2017;44(1):84-8.

10.Fasugba O, Koerner J, Mitchell BG, Gardner A. Systematic review and meta-analysis of the effectiveness of antiseptic agents for meatal cleaning in the prevention of catheter-associated urinary tract infections. Journal of Hospital Infection. 2017;95(3):233-42.

11.Clayton JL. Indwelling Urinary Catheters: A Pathway to Health Care-Associated Infections. Aorn journal. 2017;105(5):446-52.

12.Srinivas A, Kaman L, Raj P, Gautam V, Dahiya D, Singh G, et al. Comparison of the efficacy of chlorhexidine gluconate versus povidone iodine as preoperative skin preparation for the prevention of surgical site infections in clean-contaminated upper abdominal surgeries. Surgery today. 2015;45(11):1378-84. 
13.Treas LS, Wilkinson JM. Basic nursing: concepts, skills, \& reasoning: FA Davis; 2014.14.John E. Bennett RD, Martin J. Blaser. Principles and Practice of Infectious Diseases Mandell, Douglas, and Bennett's2016.

15.Cheung K, Leung P, Wong YC, To OK, Yeung YF, Chan MW, et al. Water versus antiseptic periurethral cleansing before catheterization among home care patients: A randomized controlled trial. American Journal of Infection Control. 2008;36(5):375-80.

16.Kara A, Özyürek P. The effect of periuretral care and follow-up on bacteriuria in patients with urinary catheter: A comparison of three solutions. Journal of Clinical and Experimental Investigations. 2017;8(2):62-9.

17.Thomas Fekete MSBC, MD.Allyson Bloom, MD. Catheter-associated urinary tract infection in adults. Jan 25, 2018.18.Wikström M, Levi R, Antepohl W. Bladder irrigation with Chlorhexidine reduces bacteriuria in persons with spinal cord injury. Journal of rehabilitation medicine. 2018;50(2):181-4.

19.Samimi Gh EZ, Sarokhani MR, Mosalaii S, Mehrabi Y. Effects of bladder irrigation with chlorhexidine and normal saline on prevention of bacteriuria in patient with foley catheter. Journal of Faculty of Nursing \& Midwifery of Shaheed Beheshti University of Medical Sciences and Health Services. 2010(20(70): 23-7).

20.Azadmanesh Y, Azimian J, Jahani Hashemi H, Shahrokhi A, Naemian S. Comparing the effect of washing meatus urinary region with chlorhexidine and poidon iodine solutions on the appearance of bacteriuria in patients with fixed urinary catheter suffering from brain stroke (CVA). Modern Care Journal. $2014 ; 10(4): 241-8$.

\section{Tables}

Table 1: Comparison of frequency distribution of positive bacteriuri in different time intervals between CHG and 10\% povidone-iodine groups.

\begin{tabular}{l|l|l|l|l|l|lr|}
\hline \multicolumn{2}{l|}{$\begin{array}{l}\text { hi-Square } \\
\text { sst }\end{array}$} & $\begin{array}{l}10 \% \\
\text { group povidone-iodine }\end{array}$ & \multicolumn{2}{l|}{ CHG group } & & \\
\hline & $\chi 2$ & percentage & Number & Percentage & Number & Time & \\
\hline .76 & 0.09 & 19.4 & 7 & 16.7 & 6 & $\begin{array}{l}\text { Immediately } \\
\text { catheterization }\end{array}$ & after \\
\hline .22 & 1.53 & 72.2 & 26 & 58.3 & 21 & $\begin{array}{l}72 \text { hours after } \\
\text { catheterization }\end{array}$ \\
\hline .50 & - & 94.4 & 34 & 97.2 & 35 & $\begin{array}{l}5 \text { days after } \\
\text { catheterization }\end{array}$ \\
\hline
\end{tabular}


Table 2: Frequency distribution of positive pyuria in different time intervals between CHG and $10 \%$ povidone-iodine groups

\begin{tabular}{l|l|l|l|l|l|lr|}
\hline \multicolumn{2}{l}{ i-Square } & \multicolumn{2}{l|}{$\begin{array}{l}10 \% \text { povidone-iodine } \\
\text { group }\end{array}$} & \multicolumn{2}{l|}{ CHG group } & & \\
\hline & $\chi 2$ & percentage & Number & Percentage & Number & Time & \\
\hline 30 & 0.06 & 36.1 & 13 & 33.3 & 12 & $\begin{array}{l}\text { Immediately after } \\
\text { catheterization }\end{array}$ \\
\hline 3 & 4.15 & 80.3 & 30 & 63.9 & 23 & $\begin{array}{l}72 \text { hours after } \\
\text { catheterization }\end{array}$ \\
\hline 04 & 8.13 & 86.1 & 31 & 55.6 & 20 & $\begin{array}{l}5 \text { days after } \\
\text { catheterization }\end{array}$ \\
\hline
\end{tabular}

Table3: Mean of micro-organism number in different time intervals between CHG and 10\% povidone-iodine group

\begin{tabular}{l|l|l|l|l|l|l|}
\hline $\begin{array}{l}\text { Iann- Whitney } \\
\text { sst }\end{array}$ & $\begin{array}{l}10 \% \text { povidone-iodine } \\
\text { group }\end{array}$ & \multicolumn{2}{|c|}{ CHG group } & \\
\hline & Z & $\begin{array}{l}\text { Standard } \\
\text { deviation }\end{array}$ & Mean & $\begin{array}{l}\text { Standard } \\
\text { deviation }\end{array}$ & Mean & Time \\
\hline .93 & 0.08 & 10019.53 & 3125.22 & 20419.51 & 6972.22 & $\begin{array}{l}\text { Immediately after } \\
\text { catheterization }\end{array}$ \\
\hline .43 & 0.80 & 30538.25 & 17527.78 & 34123.97 & 20180.56 & $\begin{array}{l}72 \text { hours after } \\
\text { catheterization after }\end{array}$ \\
\hline .61 & 0.51 & 41688.20 & 46277.78 & 46277.78 & 40430.56 & $\begin{array}{l}5 \text { days afteterization } \\
\text { cather }\end{array}$ \\
\hline
\end{tabular}

\section{Figures}




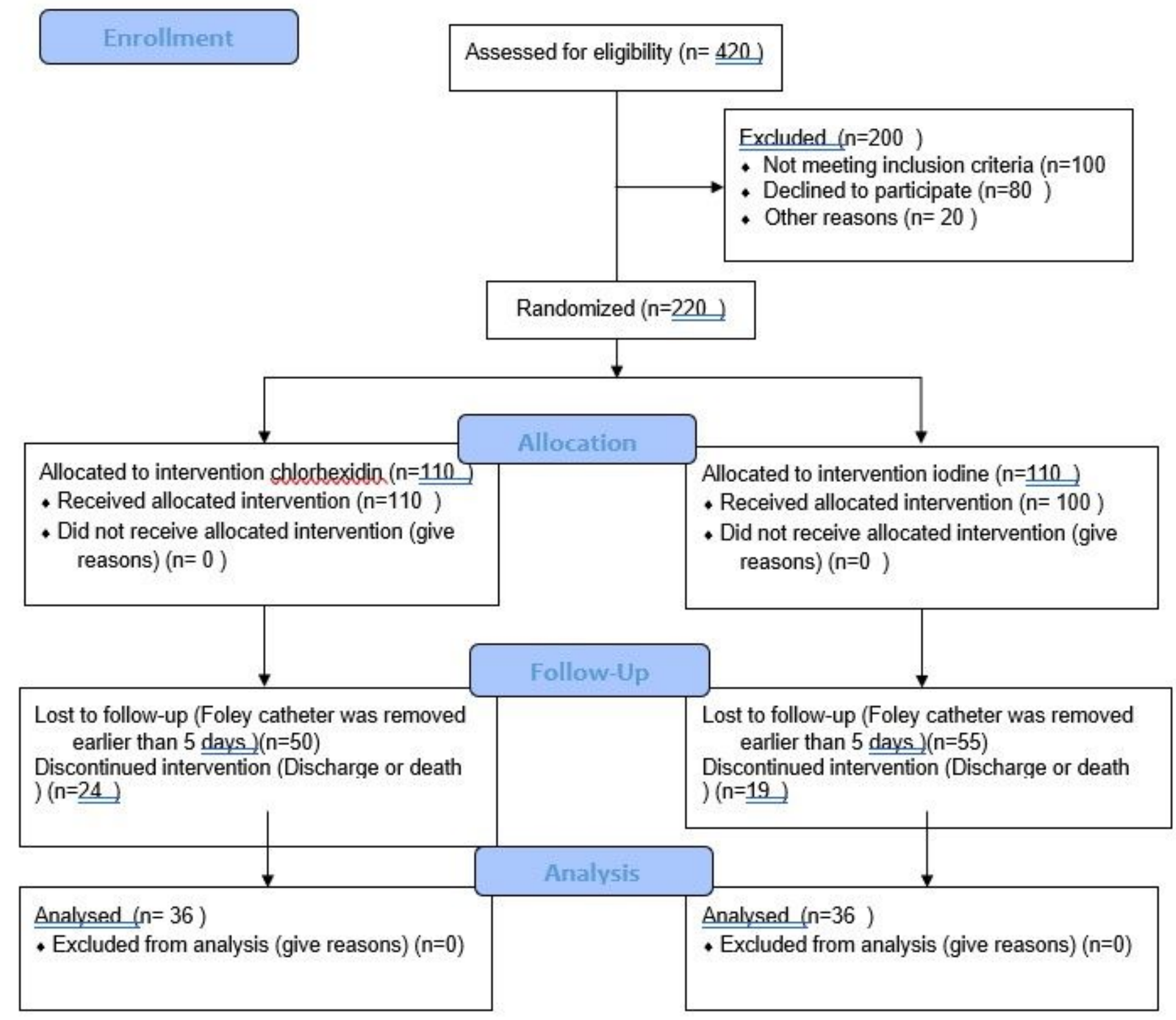

Figure 1

CONSORT Flow Diagram 